\title{
Gender differences in pediatric cardiac surgery: The cardiologist's perspective
}

Wanda C. Miller-Hance, MDa

Theresa A. Tacy, MD

See related editorial on page 4.

From the Department of Anesthesiology and Pediatrics (Cardiology), Baylor College of Medicine, Houston, Tex, ${ }^{a}$ and the Department of Pediatrics (Cardiology), University of California, San Francisco, Calif. $^{\text {b }}$

Received for publication March 30, 2004; revisions received April 6, 2004; accepted for publication April 16, 2004.

Address for reprints: Wanda C. MillerHance, MD, Baylor College of Medicine, SM1003, One Baylor Plaza, Houston, TX 77030 (E-mail: wmh@bcm.tmc.edu).

J Thorac Cardiovasc Surg 2004;128:7-10

$0022-5223 / \$ 30.00$

Copyright (C) 2004 by The American Association for Thoracic Surgery

doi:10.1016/j.jtcvs.2004.04.008

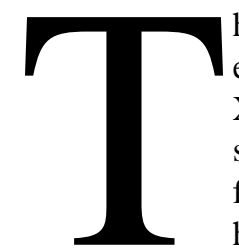

here is much evidence that gender differences become manifest very early in life; in fact, they may begin before life. Sperm carrying the $\mathrm{X}$ chromosome differ in motility from the $\mathrm{Y}$ chromosome-bearing sperm. ${ }^{1,2}$ Once the ovum is fertilized, genetically normal male fetuses have a higher death rate than female fetuses. ${ }^{3}$ Neonatologists have long noted gender differences in their practice. Boys are more likely to be delivered prematurely. ${ }^{4}$ Deaths resulting from respiratory distress syndrome $^{5}$ and neonatal neurologic complications ${ }^{6}$ are greater for boys. Preterm girls have higher levels of beneficial catecholamines than boys, ${ }^{7}$ and this may account for their better outcomes.

Despite these indications that gender may affect the impact of disease in children, investigations into gender influences in congenital heart disease (CHD) are sparse. When compared with information on gender differences in adult acquired heart disease incidence, treatment, and outcome, there is a relative dearth of information regarding these data in congenital or acquired heart disease in children. The reason for this is likely due to multiple factors and is probably broader than the assumption that before adolescence, the cardiovascular physiology is unaffected by gender. For instance, the delay in diagnosis and treatment in women with ischemic heart disease that was so well documented in the 1990s is not likely to be found in infant girls with significant heart disease, because the presentation of CHD is often quite objective. Treatment in adult cardiology may have been biased in the past by exclusion of women from randomized drug trials, yet prospective clinical trials are much less common in pediatric cardiology ${ }^{8}$ for many reasons, including small numbers of patients, lack of treatment uniformity both between centers and over time within centers, and the need for multicenter trials. When a prospective clinical trial is performed, patient recruitment is difficult enough that exclusion of one gender is practically unthinkable.

Despite the paucity of investigations, there are aspects of CHD in which a gender effect is known or suspected.

\section{Incidence}

Approximately 32,000 infants in this country are born each year with CHD, making it the leading cause of birth defects. This equates to 8 cases per 1000 live births of the more than 4 million children born yearly in this country. Nearly $40 \%$ of patients with CHD will require a surgical intervention to palliate or correct their condition at some point during their lifetime. This accounts for more than 20,000 yearly surgical procedures performed in the United States for CHD.

Patterns of gender predominance have been noted in several cardiovascular malformations, and these are summarized in Table 1. Several consistencies appear: D-transposition of the great arteries, left-sided obstructions, and double-outlet right ventricle have a strong male predominance, whereas more girls present with patent ductus arteriosus, secundum atrial septal defect, and Ebstein anomaly of the tricuspid valve. Other lesions, such as ventricular septal defect and truncus, seem to be equally distributed between sexes. The reasons for these observed patterns have not been identified. 
TABLE 1. The gender ratio observed for specific types of CHD, described as male/female ratio of incidence

\begin{tabular}{lccc}
\hline Diagnosis & Samanek $^{\mathbf{9}}$ & $\begin{array}{c}\text { Calzolari and } \\
\text { colleagues }^{\mathbf{1 0}}\end{array}$ & $\begin{array}{c}\text { Samanek and } \\
\text { colleagues }^{\mathbf{1 1}}\end{array}$ \\
\hline All & $1.09: 1$ & $1: 1$ & $1.28: 1$ \\
PDA & $1: 1.7$ & & \\
ASD, secundum & & $1: 1.4$ & $1: 1.5$ \\
VSD & & $1: 1.11$ & $1: 1$ \\
Aortic stenosis & $1.95: 1$ & & $1.6: 1$ \\
CoA & $1.3: 1$ & & $1.6: 1$ \\
HLHS & $2.6: 1$ & & $1.4: 1$ \\
Pulmonary atresia & $1.55: 1$ & $1.14: 1$ & $1.7: 1$ \\
Tricuspid atresia & $1.45: 1$ & & \\
Ebstein anomaly & $1: 1.6$ & & \\
TOF & $1: 1.1$ & $1.04: 1$ & $1.4: 1$ \\
DORV & $2.7: 1$ & & $1.7: 1$ \\
TGA & $2.11: 1$ & $2.23: 1$ & $2.1: 1$ \\
Truncus arteriosus & $1: 1.2$ & $1: 1.11$ & $1.3: 1$
\end{tabular}

$P D A$, Patent ductus arteriosus; $A S D$, atrial septal defect; $V S D$, ventricular septal defect; $C O A$, coarctation of the aorta; $H L H S$, hypoplastic left heart syndrome; TOF, tetralogy of Fallot; DORV, double-outlet right ventricle; $T G A$, transposition of the great arteries.

\section{Genetic Syndromes and CHD}

The pathogenesis of CHD is complex. Although in most cases no underlying cause is identified, a number of welldescribed genetic syndromes are known to have associated cardiovascular malformations. Some of these include Down, DiGeorge, Holt-Oram, Noonan, William, and Marfan syndromes. In most autosomal disorders, no significant gender predominance is recognized. Aneuploidy of the sex chromosomes, however, results in particular gender phenotypes that may exhibit specific patterns of cardiovascular malformations: such is the case with Turner syndrome.

Turner syndrome is a chromosomal disorder that exclusively affects girls and women. It is associated with monosomy of the X chromosome (XO karyotype), mosaicism, or structural abnormalities of the $\mathrm{X}$ chromosome, such as partial deletion or ring formation. Structural heart disease occurs in approximately $25 \%$ of patients with Turner syndrome: the most common are bicuspid aortic valve, coarctation of the aorta, aortic root dilation, and more severe forms of left-sided obstruction, such as hypoplastic left heart syndrome. An even higher incidence of CHD (62\%) has been identified prenatally by fetal echocardiography. ${ }^{12}$ The typical fetal presentation of Turner syndrome has an extremely poor prognosis for intrauterine survival. ${ }^{12}$

An increased risk of ischemic heart disease, hypertension, stroke, type 2 diabetes, and aortic dissection has been reported in patients with Turner syndrome; this may be due in part to insulin resistance. ${ }^{13}$ The increased prevalence of coronary artery disease in these women has been attributed to the effects of premature ovarian failure. However, a recent report demonstrated unfavorable lipid profiles in healthy, young, nonobese women with Turner syndrome, suggesting that this may also play a role in their cardiovascular morbidity. ${ }^{14}$ Current recommendations are for all patients with Turner syndrome-regardless of age, CHD, or aortic root dilation - to undergo routine cardiovascular surveillance.

\section{Natural History of CHD}

The clinical outcome in CHD is strongly influenced by the anatomic diagnosis and the likelihood of successful palliation or "correction." Whereas the influence of cardiac diagnosis is a more likely determinant than gender of mortality, other differences in the long-term status and care may be related to gender. In a recent multi-institutional study on 1245 adults with CHD, women were more likely to be married, insured, or both, whereas men were more likely to take antihypertensive drugs, afterload-reducing agents, and antiarrhythmic drugs. ${ }^{15}$

Many studies show no gender effect on morbidity in patients with CHD, such as a study of 495 patients who underwent surgery for tetralogy of Fallot/pulmonary atresia between 1977 and 1999. ${ }^{16}$ More recent data indicate that girls are at a higher risk for hospital mortality, for reasons that are unclear. ${ }^{17}$ This seems to be mirrored in another study of outcomes for CHD patients who required postoperative extracorporeal membrane oxygenator support. This study reported an increased risk of death by a factor of 5.43 for female patients. ${ }^{18}$ The companion editorial in this issue by Azakie and colleagues addresses the effect of gender on surgery for congenital heart disease.

\section{Arrhythmias}

Increasing evidence for gender-related differences in cardiovascular disease extends to the area of electrophysiology and arrhythmias. In one small series of perinatal supraventricular tachycardia (33 patients), a male/female ratio of 2.7:1 was noted. ${ }^{19}$ Congenital third-degree atrioventricular block overall has a slight female dominance $(66 \%$ in one large series ${ }^{20}$ ), and all patients were female in a study of acquired childhood complete heart block with a recent history of viral illness. ${ }^{21}$

A prevalence of women among adult symptomatic patients with long QT syndrome is well described. Adult women have a longer QT interval and are more prone than men to the development of torsades de pointes. But are these differences present at birth? A study designed to address this question demonstrated slightly higher heart rates in female infants than in male infants but failed to identify disparity in the corrected QT interval (QTc) among babies by gender. ${ }^{22}$ This suggests a potential hormonal influence on the QTc that is possibly initiated around the time of puberty. It is also recognized that the specific long QT syndrome genotype influences the probability of cardiac 
events differently in female and male children. ${ }^{23}$ A lower incidence of cardiac events during childhood for female patients with the LTQS-1 variant has been reported, whereas it is higher in women during adulthood than in men. These types of data, along with many other observations, underscore the role of gender-specific differences in the nature and frequency of specific cardiac rhythm disorders.

\section{Exercise and Esteem}

In healthy children, boys have better exercise performance than girls because of their greater lean body mass, stroke volume, and maximum oxygen consumption. ${ }^{24}$ Healthy adolescent females report lower self-esteem, less exercise, and poorer heath status than do their male peers. ${ }^{25}$ These traits are seemingly reversed in children with CHD. Male adolescents with CHD have lower perceived exercise capacity and self-esteem. This was not true for adolescent girls with CHD. The negative self-concept of boys with CHD may be partly explained by reduced physical ability interfering with peer relationships. ${ }^{26,27}$ These observations may be important in the assessment of reported symptoms, which may in some cases be the basis for referral for surgical intervention when objective indications are lacking.

\section{Pregnancy Outcomes in CHD}

The assessment of outcomes during pregnancy in women with CHD is challenged by several factors. First, there is a wide morphologic spectrum of CHD; thus, investigators must limit their study population to a specific physiologic group. Even then, studies that focus on specific diagnoses are limited by heterogeneity of the patient population with regard to prior and current therapies (medical and surgical), age at operation, residual defects, and physiologic variability. Patients operated on in an earlier surgical era may have complications or residua different from those of patients operated on more recently. Finally, the inability to accumulate a large number of pregnant patients with a specific pathologic condition at a single institution often requires multicenter studies, and this introduces the potential problem of institution bias in outcome.

Despite the challenges confronted by these studies, it is well documented that a significant number of women with CHD can have a successful pregnancy with proper care. Outcome is generally favorable in women if their functional class and systolic ventricular function are good. Risk factors for poor maternal/fetal outcomes include severe ventricular dysfunction, poor functional status, uncontrolled rhythm disturbances, cyanotic conditions, increased pulmonary vascular resistance, and severe right ventricular hypertension. The highest risk of maternal death is in patients with Eisenmenger syndrome, for which the total estimated risk is approximately $40 \%$. Current recommendations state that women with New York Heart Association functional class III or IV symptoms, significant systemic ventricular dysfunction, or severe systemic atrioventricular valve regurgitation should be counseled against pregnancy. Other highrisk patients include those with severe aortic stenosis or coarctation and those with Marfan syndrome and associated aortic root dilatation.

Certain types of repaired CHD in the mother pose minimal risk. For example, after repair, the risk of pregnancy complications in women with tetralogy of Fallot is comparable with that of the general population. ${ }^{28,29}$ However, maternal Fontan physiology may pose significant risks during pregnancy. The modified Fontan procedure, a final pathway for many cyanotic women in whom a biventricular repair is not feasible, provides eventual separation of the pulmonary and systemic circulations. Considerations in patients after the Fontan operation relate to a limited ability to increase their cardiac output, the morbidity associated with chronic increases of systemic venous pressures, and the potential for development of late complications. These issues raise significant concerns regarding the ability of a pregnant post-Fontan patient to tolerate the hemodynamic burden that accompanies pregnancy and delivery. Although successful pregnancies have been reported in women with good hemodynamic results, many continue to counsel against pregnancy because of the potential risks to the mother and her infant. ${ }^{30}$ An increased incidence of firsttrimester miscarriage has been documented in these patients.

The incidence of cardiovascular anomalies in first-degree relatives is approximately $3 \%^{31}$; thus, the risk for offspring of women with CHD is known to be higher than that identified in the healthy population. For this reason, fetal echocardiography is strongly advised and plays a critical role in prenatal counseling. The risk of a child of a mother with CHD having a cardiac lesion is higher than if the father has CHD.

\section{Summary}

Whereas gender issues are not at the forefront of concerns facing pediatric cardiologists and congenital heart surgeons, there are circumstances in which gender may play a role in the care and outcome of a patient with CHD. However, any effect at this time is likely subtle, and large studies are necessary to reveal any such effects. The use of large registries and multi-institutional studies will foster investigation into possible gender effects, and this may further improve the care of these patients.

\section{References}

1. Rose GA, Wong A. Experiences in Hong Kong with the theory and practice of the albumin column method of sperm separation for sex selection. Hum Reprod. 1998;13:146-9.

2. Khatamee MA, Horn SR, Weseley A, Farooq T, Jaffe SB, Jewelewicz 
R. A controlled study for gender selection using swim-up separation. Gynecol Obstet Invest. 1999;48:7-13.

3. Hassold T, Quillen SD, Yamane JA. Sex ratio in spontaneous abortions. Ann Hum Genet. 1983;47(Pt 1):39-47.

4. Ingemarsson I. Gender aspects of preterm birth. BJOG. 2003; 110(suppl 20):34-8.

5. Khoury MJ, Marks JS, McCarthy BJ, Zaro SM. Factors affecting the sex differential in neonatal mortality: the role of respiratory distress syndrome. Am J Obstet Gynecol. 1985;151:777-82.

6. Ingemarsson I, Herbst A, Thorngren-Jerneck K. Long term outcome after umbilical artery acidaemia at term birth: influence of gender and duration of fetal heart rate abnormalities. Br J Obstet Gynaecol. 1997;104:1123-7.

7. Greenough A, Lagercrantz H, Pool J, Dahlin I. Plasma catecholamine levels in preterm infants. Effect of birth asphyxia and Apgar score. Acta Paediatr Scand. 1987;76:54-9.

8. Gidding SS, Benson DW, Clark EB, Rocchini AP. Pediatric cardiology research in 1990: a review of abstracts submitted to the Society for Pediatric Research, American Academy of Pediatrics, and American Heart Association Scientific Sessions. Pediatr Res. 1992;32:10-6.

9. Samanek M. Boy:girl ratio in children born with different forms of cardiac malformation: a population-based study. Pediatr Cardiol. 1994;15:53-7.

10. Calzolari E, Garani G, Cocchi G, Magnani C, Rivieri F, Neville A, et al. Congenital heart defects: 15 years of experience of the EmiliaRomagna Registry (Italy). Eur J Epidemiol. 2003;18:773-80.

11. Samanek M, Goetzova J, Benesova D. Distribution of congenital heart malformations in an autopsied child population. Int J Cardiol. 1985; 8:235-50.

12. Surerus E, Huggon IC, Allan LD. Turner's syndrome in fetal life. Ultrasound Obstet Gynecol. 2003;22:264-7.

13. Gravholt $\mathrm{CH}$. Medical problems of adult Turner's syndrome. Horm Res. 2001;56(suppl 1):44-50.

14. Cooley M, Bakalov V, Bondy C. Lipid profiles in women with $45, X$ vs 46,XX primary ovarian failure. JAMA. 2003;290:2127-8.

15. Ahmed S, King M, Sijbom M, de Moor M, Liberthson R, Child J, et al. Gender differences in adults with congenital heart disease: a population profile from the International Society for Adult Congenital Cardiac Disease [abstract P68]. Circulation. 2003;107:e131-84.

16. Cho JM, Puga FJ, Danielson GK, Dearani JA, Mair DD, Hagler DJ, et al. Early and long-term results of the surgical treatment of tetralogy of Fallot with pulmonary atresia, with or without major aortopulmonary collateral arteries. J Thorac Cardiovasc Surg. 2002;124:70-81.

17. Chang RK, Chen AY, Klitzner TS. Female sex as a risk factor for in-hospital mortality among children undergoing cardiac surgery. Circulation. 2002;106:1514-22.

18. Johnson TR, Schamberger MS, Hart JC, Turrentine MW, Brown JW. After repair, atrioventricular valve regurgitation during cardiac extracorporeal membrane oxygenation predicts survival. Ann Thorac Surg. 2003;76:848-52.

19. Smith MB, Colford D, Human DG. Perinatal supraventricular tachycardia. Can J Cardiol. 1992;8:565-8.

20. Eronen M, Siren MK, Ekblad H, Tikanoja T, Julkunen H, Paavilainen T. Short- and long-term outcome of children with congenital complete heart block diagnosed in utero or as a newborn. Pediatrics. 2000;106(1 Pt 1):86-91.

21. Khongphatthanayothin A, Chotivitayatarakorn P, Benjacholamas V, Muangmingsuk S, Lertsupcharoen P, Thisyakorn C. Complete heart block in children at King Chulalongkorn Memorial Hospital. J Med Assoc Thai. 2001;84(suppl 1):S111-7.

22. Stramba-Badiale M, Spagnolo D, Bosi G, Schwartz P. Are gender differences in QTc present at birth? MISNES Investigators. Multicenter Italian Study on Neonatal Electrocardiography and Sudden Infant Death Syndrome. Am J Cardiol. 1995;75:1277-8.

23. Zareba W, Moss A, Locati E, Lehmann M, Peterson D, Hall W, et al. International Long QT Syndrome Registry. Modulating effects of age and gender on the clinical course of long QT syndrome by genotype. $J$ Am Coll Cardiol. 2003;42:103-9.

24. Rowland T, Goff D, Martel L, Ferrone L. Influence of cardiac functional capacity on gender differences in maximal oxygen uptake in children. Chest. 2000;117:629-35.

25. Garcia AW, Broda MA, Frenn M, Coviak C, Pender NJ, Ronis DL. Gender and developmental differences in exercise beliefs among youth and prediction of their exercise behavior. $J$ Sch Health. 1995;65:213-9.

26. Sticker E, Schmidt C, Steins G. Self esteem of chronically ill children and adolescence exemplified by obesity and congenital heart defect [in German]. Prax Kinderpsychol Kinderpsychiatr. 2003;52:17-34.

27. Salzer-Muhar U, Herle M, Floquet P, Freilinger M, Greber-Platzer S, Haller A, et al. Self-concept in male and female adolescents with congenital heart disease. Clin Pediatr (Phila). 2002;41:17-24.

28. Ralston J, Dunn M. Pregnancies after surgical correction of tetralogy of Fallot. JAMA. 1976;235:2627-8.

29. Singh H, Bolton PJ, Oakley CM. Pregnancy after surgical correction of tetralogy of Fallot. Br Med J (Clin Res Ed). 1982;285:168-70.

30. Canobbio MM, Mair DD, van der Velde M, Koos BJ. Pregnancy outcomes after the Fontan repair. J Am Coll Cardiol. 1996;28:763-7.

31. Stoll C, Alembik Y, Roth MP, Dott B, De Geeter B. Risk factors in congenital heart disease. Eur J Epidemiol. 1989;5:382-91. 